\title{
A cidade é uma só?: autoficcionalização, interrogação do arquivo e sentido de dissenso
}

\section{Mariana Duccini Junqueira da Silva}

Doutora; Insper Instituto de Ensino e Pesquisa

marianaduccini@yahoo.com.br

\section{Resumo}

Por meio da articulação de duas estratégias fílmicas - a autoficcionalização dos personagens e a ressignificação de materiais de arquivos oficiais -, o documentário A cidade é uma só? propõe uma crítica radical ao discurso de poder que circunscreveu a Campanha de Erradicação das Invasões (CEI), iniciativa que removeu populações pobres da área central de Brasília, levando-as a formar as então chamadas cidadessatélites dos anos 70. Este trabalho propõe-se a uma análise do documentário de Adirley Queirós com vistas a apreender, pela materialidade fílmica, os modos como a obra viabiliza a ressignificação de uma memória coletiva à medida que os protagonistas se empoderam de representações sociais que colidem com as disposições do poder estabelecido. O próprio enunciado fílmico, assim, estrutura-se pelo sentido de dissenso, como aquilo que é próprio de uma política da arte (RANCIÈRE, 2005b).

\section{Palavras-chave}

A cidade é uma só?. Documentário. Autoficcionalização. Arquivo. Dissenso.

\section{Introdução}

No início dos anos 70, um jingle oficial do governo do Distrito Federal, veiculado pela televisão, trazia um grupo de crianças de escolas primárias que entoavam o verso: "Ajudenos a construir nosso lar para que possamos dizer juntos: 'A cidade é uma só'”. A propaganda alinhava-se ao contexto da Campanha de Erradicação das Invasões (CEI), iniciativa que removeu populações pobres do Plano Piloto, levando-as a formar as então 
chamadas cidades-satélites. Ceilândia, a primeira delas, traz no nome a marca literal do processo que institucionalizou a expulsão, removendo as favelas do centro de poder político do país.

Ao questionar radicalmente os procedimentos e resultados da ação, o documentário $A$ cidade é uma só? dirigido por Adirley Queirós (2011) é estruturado em chave de confronto e desestabilização do discurso oficial daquela campanha. A interrogação que se incorpora ao título reverbera por todo o enunciado fílmico, instalando o sentido de dissenso que é próprio de uma política da arte: com a possibilidade de opor um mundo a outro pela reconfiguração de um universo sensorial que determina modos de vida e de relações intersubjetivas:

[A arte] é política enquanto recorta um determinado espaço ou um determinado tempo, enquanto os objetos com os quais ela povoa esse espaço ou o ritmo que ela confere a esse tempo determinam uma forma de experiência específica [...]: uma forma específica de visibilidade. (RANCIÈRE, 2005b, documento eletrônico não paginado).

A releitura de um passado histórico, terreno comum aos três personagens principais do documentário (Nancy, Dildu e Zé Antônio), resulta, por parte deles, em intervenções no presente, materializadas por modos singulares de negociação com essa memória. A experiência subjetiva é então ressignificada à medida que os protagonistas se empoderam ${ }^{1}$ de novas formas de representações sociais que colidem com as disposições do poder estabelecido.

Se tais representações são entendidas como plataformas "[...] que tanto nos orientam em direção ao que é visível como àquilo a que nós temos de responder; ou que relacionam a aparência à realidade." (MOSCOVICI, 2010, p. 31), é razoável inferir que a dinâmica das representações responde pela própria construção de determinada realidade, mobilizando efeitos de evidência que, no documentário de Queirós, serão desnaturalizados.

O dispositivo do filme, nesse âmbito, mobiliza duas estratégias complementares: a potencialidade de autoficcionalização dos personagens e o questionamento crítico dos materiais de arquivo apresentados no filme (não raro articulados de forma que a faixa sonora contradiga a imagética, instilando a ironia no interior dos discursos autorizados).

\footnotetext{
${ }^{1} 0$ conceito de empoderamento subsume, no âmbito destas reflexões, “[...] o processo por meio do qual indivíduos e grupos sociais ampliam a capacidade de configurar suas próprias vidas, a partir de uma evolução na compreensão sobre suas potencialidades e sua inserção na sociedade. Não se trataria, em princípio, somente de uma questão de aumento de poder e autonomia individual ou de elevação de auto-estima, mas da aquisição de uma consciência coletiva da dependência social e da dominação política." (FREIRE FILHO, 2007, p. 17). Sublinhamos, em tal acepção, a importância fundamental da capacidade reflexiva dos sujeitos quanto a seus modos de participação nas práticas cotidianas no referido processo.
} 
Nosso intento analítico orienta-se pelo exame, em termos descritivos, das materialidades imagéticas e sonoras que se articulam para viabilizar esses dois efeitos expressivos, possibilitando, em termos interpretativos, a remissão ao todo do enunciado com vistas à depreensão de como se efetivam os sentidos propostos pela obra, e assim: “[...] compreender como [os elementos isolados] se associam e se tornam cúmplices para fazer surgir um todo significante". (VANOYE; GOLIOT-LÉTÉ, 1994, p. 15).

Tornam-se exemplares da associação entre as referidas estratégias as sequências que trazem imagens e sons de arquivo da gravação do jingle oficial 'A cidade é uma só' e as que propõem uma espécie de reconstituição deste evento pretérito, com a convocação (como gesto do documentário) de crianças que, no presente, ecoariam outra vez as vozes do poder.

Enfileiradas e uniformizadas, agora as crianças não cantam: não mais emprestam suas expressões à versão oficial. Por um recurso de montagem, o fluxo da ação é interrompido com o corte do plano, propulsionando o sentido de embate com uma configuração de poder que não apenas alienou os sujeitos de seu corpo e de sua voz, mas das próprias relações que poderiam estabelecer com o espaço público em que estavam inseridos.

\section{0 dissenso como experiência política: reconfigurações de modos de ver, sentir, saber}

Se é próprio da arte em sua dimensão política o estabelecimento de um sentido de dissenso, isso não se dá exatamente via confrontação direta de ideias ou de conteúdos programáticos entre grupos sociais, nem mesmo em face de uma intervenção imediata na realidade, mas como uma operação capaz de reconfigurar um espaço sensorial partilhado. 0 dissenso se instala na medida em que apresenta novos horizontes de enunciabilidade, redefinindo modos de ver e de sentir, além de atribuir valor às experiências cotidianas e conformar as relações afetivas e cognitivas entre os sujeitos e deles com o mundo.

Uma operação de dissenso, portanto, é aquela que antes de tudo desnaturaliza formas consensuais de divisão estabelecida entre práticas, saberes e modos coletivos de participação. Também, expõe e questiona a própria natureza de tal divisão, explicitando um litígio até então tornado invisível, aquele que reivindica a "parte dos sem-parte":

Não há política porque os homens, pelo privilégio da palavra, põem seus interesses em comum. Existe política porque aqueles que não têm direito de ser contados como seres falantes conseguem ser contados, e instituem uma comunidade pelo fato de colocarem em comum o dano que nada mais é que o próprio enfrentamento, a contradição de dois mundos alojados num só: o mundo em que estão e aquele em que não estão, o mundo onde 
há algo "entre" eles e aqueles que não os conhecem como seres falantes e contáveis e o mundo onde não há nada. (RANCIÈRE, 1996, p. 40, grifo do autor).

Com o recurso da ficcionalização, de um rearranjo de certo "estado das coisas", o enunciado de $A$ cidade é uma só? contempla três personagens que buscam reinscrever suas presenças subjetivas no anteparo da história, estabelecida como a narrativa autorizada da Campanha de Erradicação de Invasões. 0 sentido de ficção que aqui assumimos é o de um trabalho que "[...] muda as coordenadas do representável; muda nossa percepção dos acontecimentos sensíveis, nossa maneira de relacioná-los com os sujeitos, o modo como nosso mundo é povoado de acontecimentos e figuras". (RANCIÈRE, 2012, p. 64).

Nancy, cantora de rádio, foi uma das crianças que participaram da propaganda do governo na época das remoções e, como outras tantas pessoas, foi expulsa da casa onde vivia com a família. Entoando, sob um arranjo musical diferente do original, a canção outrora popularizada, a personagem reflete que “[...] o que eles [políticos] queriam era um lugar para jogar aquele monte de pobre".

Dildu, sobrinho de Nancy, parece não ter vivido diretamente o contexto da remoção, mas certamente sofreu seus efeitos ambivalentes: vaga pelas ruas da Capital, entre a paisagem do Plano Piloto e a da periferia, e assume um discurso crítico quanto à disposição de poder que assim configurou sua vida e a de seus amigos. Surge ora como faxineiro, ora como candidato a deputado distrital pelo fictício PCN (Partido da Correria Nacional), investindo contra a "hereditariedade no serviço público" que "desde 1500" determina quem ocupará cargos de prestígio.

Zé Antônio, cunhado de Dildu, divide seu cotidiano entre a venda de terrenos e o apoio à "candidatura" do parente: exercendo muitas vezes o papel de motorista, conselheiro e cabo eleitoral, acompanha o cunhado na aventura política. Com ele, percorre descampados em que se avistam, em profundidade de campo, a Esplanada dos Ministérios e o Congresso Nacional. Em seguida, deslocando-se em direção a essa paisagem, os personagens lentamente se aproximam dos edifícios, encurtando simbolicamente a distância que ao mesmo tempo os afasta do núcleo do poder e que se figurativiza como um trajeto redentor: a possibilidade de enlaçar suas vidas a uma nova forma de ficção, a uma ordem do mundo até então inédita.

Dois regimes de ficção, enquanto ordenadores de plataformas imaginárias que dão sentido às existências individuais e à realidade circundante, são assim dispostos em uma relação polêmica. Convocado e ao mesmo tempo questionado, o discurso oficial (com suas 
estratégias de distribuição consensual de lugares subjetivos e de valoração de práticas coletivas) é fissurado em sua própria lógica e exposto em sua condição de construto como gesto político em A cidade é uma só?. Trata-se, então, de uma disputa de sentidos não apenas pela conformação de novos modos de autorrepresentação pelos sujeitos do filme, mas também pelo estabelecimento de uma nova possibilidade de consenso, do que é próprio ao sentido da história.

O enunciado do documentário, entretanto, reconhece e explicita seus limites, inerentes a toda manifestação de arte na contemporaneidade, ela mesma política na medida de um afastamento de ordem ético-estética. Se tal distância torna implausível a intervenção direta na realidade, ao mesmo tempo faculta a imaginação (a produção de um conjunto de imagens) de universos sensoriais que desafiam os regimes de visibilidade cristalizados:

As artes nunca emprestam às manobras de dominação ou de emancipação mais do que podem emprestar, ou seja, muito simplesmente, o que têm em comum com elas: posições e movimentos dos corpos, funções da palavra, repartições do visível e do invisível. (RANCIÈRE, 2005a, p. 26).

Em lugar de elidir essa distância autoinvestindo-se como espécie de porta-voz da versão dos "removidos pelo poder", o filme expõe seus mecanismos de construção, dá-se ao olhar do espectador como o próprio resultado de um olhar (o da instância autoral). Para além dessas estratégias de reflexividade, o dispositivo suscita em relação a seus personagens - caso mais evidente em Dildu e em Zé Antônio - a possibilidade de uma atuação dramática em sentido estrito e suscita uma camada de representação que se sobrepõe àquela própria a todo sujeito posto em filme, quando se transforma de ator social em ator natural (SANTEIRO, 1978).

Exorbitando essa "conversão" própria da dramaturgia natural, a autoficcionalização, estratégia que compõe o regime enunciativo de A cidade é uma só?, garante expressividade a um universo sensorial "inventado", em que as formas de afirmação dos sujeitos tendem à fantasia, princípio que "[...] estrutura o excesso que resiste à nossa imersão na realidade cotidiana". (ZIZEK, 2003, p. 32). 0 recurso da autoficcionalização, assim, não deixa espaço à dicotomização entre vida concreta e invenção; contempla, mas também extrapola, certo julgamento valorativo que buscaria estabelecer a versão mais "legítima" acerca de determinado acontecimento social.

[...] a personagem deixou de ser real ou fictícia, tanto quanto deixou de ser vista objetivamente ou de ver subjetivamente: é uma personagem que vence passagens e fronteiras porque inventa enquanto personagem real, $\mathrm{e}$ torna-se tão mais real quanto melhor inventou [...]. É preciso que a 
personagem seja primeiro real, para afirmar a ficção como potência e não como modelo: é preciso que ela comece a fabular para se afirmar ainda mais como real, e não como fictícia. (DELEUZE, 2007, p. 184, grifo do autor).

A realidade da invenção materializa desejos e fantasias latentes, dando a eles uma forma sensível, e propõe feixes de endereçamento dos sujeitos a um passado histórico passível de ressignificação; dos personagens ao filme e a um universo espectatorial e do próprio filme ao contexto das produções contemporâneas de cultura, espaço gerador de formas estéticas que passam a recompor os circuitos de significados atribuídos às práticas sociais.

\section{Autoficionalização: o falso como afirmação de um verdadeiro}

Um efeito sonoro que lembra o ruído de tiros anuncia o início de um jingle eleitoral de um "candidato" a deputado distrital cuja plataforma promete "ensino público para passar em concursos", jornadas de trabalho de 30 horas semanais (porque está na hora de os trabalhadores "viverem um pouco") e cinema na praça ao módico preço de um real (com "filmes de bangue-bangue e caratê"), entre outras iniciativas. Mas e os tiros? "Pode ser de gângster, pode ser de político", responde o candidato, Dilmar Durães, ou simplesmente Dildu.

Autofabulando-se como um pleiteante a tomar parte no sistema político estabelecido, o personagem adota gestos típicos e uma fala que tem por vezes inflexão populista. No exagero dessas expressões, simula (ou dissimula) o corpo-a-corpo próprio às campanhas - e insinua, pela ação deliberadamente dramática, os maneirismos de um universo que pode ser tanto de gângster quanto de político.

Nessa ambivalência, Dildu, o personagem, emerge como o anticandidato: sem a pompa e a experiência comuns às campanhas de políticos fluentes na linguagem do poder, ele conta apenas com a ajuda do fiel cunhado Zé Antônio, que dirige o decrépito carro que o conduz ao trabalho junto aos possíveis eleitores.

Dos três protagonistas do documentário, Dildu é certamente aquele cuja construção mais exercita a potência do falso (DELEUZE, 2007), entendida como a virtualidade de se afirmar uma verdade cuja força expressiva é resultado de uma construção ficcional.

Fazendo da encenação e da autenticidade, ou mais exatamente, da autenticidade da encenação, uma de suas principais estratégias enunciativas, em A cidade é uma só? a 
experiência do personagem vincula-se a uma possibilidade de reelaboração de vivências singularizantes, como forma de tensionamento da realidade ou de memórias que dão compleição a determinado modo de vida. Nesse âmbito, o personagem torna o real mais real por conjugá-lo a uma ordem de ficções, no sentido daquilo que se constrói, da ocupação de lugares até então imponderáveis.

A ampliação de um efeito de contraste entre os regimes de significação de um poder disciplinador que conformou toda uma escala de valoração das experiências sociais (em especial das potencialidades de inclusão e exclusão dos sujeitos), e os modos como esses atores se empoderam de meios expressivos para reconfigurar o espaço sensível é apresentada já na abertura do documentário.

O começo é marcado por uma faixa sonora correspondente ao período da construção da Capital, que anuncia: "Brasília, a síntese da nacionalidade, espera por você". Com o trabalho de montagem, o plano contíguo inquire na voz de Dildu: "Será?". A sequência, que torna clara a relação entre materiais e temporalidades heterogêneos, assume um tom de dissenso no interior da continuidade permeado por uma desestabilização no fluxo pretensamente harmônico e unívoco da narrativa histórica.

É assim que as vidas vividas de muitos daqueles que tributaram sua força de trabalho, expectativas e fantasias a um ideário épico faz ver o quão impertinente foi o ideal da cidade que seria "uma só". Ainda que essa configuração do sensível tenha trabalhado para instalar determinado sentido de consenso erigindo uma espécie de mito fundador, os modos como os diversos atores sociais tomaram parte neste processo não destinou ao tecido da história apenas relatos de triunfo e bem-aventurança.

Legando visibilidade a vidas que dinamizaram o "estar no mundo" do personagem no contrafluxo das narrativas estabelecidas, o documentário compõe em chave poética a sequência em que Dildu, caminhando pela Ceilândia, "encontra-se" com uma carreata eleitoral da então candidata à presidência da República Dilma Rousseff. Em tudo, o personagem se opõe à opulência da situação: em meio aos sons de rojões, buzinas e palavras de ordem, caminha em sentido oposto ao do desfile de carros, bandeiras e cartazes. Investe, determinado, em seu trajeto. Pisa a terra batida, já que a carreata, que vem tomando o asfalto, o empurra para as bordas.

Quando a sequência é retomada, Dildu peregrina solitário até encontrar casas modestas para distribuir os santinhos de sua campanha. Sentado em um gramado, em silêncio meditativo, apoia-se em um muro em que pode ser lida a frase mal composta: " $I$ os 
aplausos deichem pra depois". Sem alarde e sem aplauso, portanto, Dildu sai de cena cantando baixinho, enquanto a voz over da transmissão radiofônica de uma propaganda política alude aos "novos caminhos da civilização brasileira".

Para o personagem, o caminho civilizatório possível é o de sua "Correria Nacional", que está na direção contrária à dos estabelecidos na trama. Ficcionalizando a própria condição de existência, dirige-se ao indeterminado. Sua solidão, em marcado contraste com a multidão que havia pouco tomava o espaço da Ceilândia, incorpora paradoxalmente uma forma de relação social: aquela que emerge com a perda da vinculação coletiva em vista de um individualismo de massa, em que viceja, no entanto, “[...] a igual capacidade dos membros de uma coletividade para ser um Eu cujo juízo possa ser atribuído a qualquer outro, e criar assim [...] uma nova espécie de Nós, uma comunidade estética ou dissensual". (RANCIÈRE, 2012, p. 63, grifos do autor).

Nos limites de uma experiência estética, o documentário A cidade é uma só? torna possível essa nova espécie de "Nós": a investida política de Dildu, construída em termos de artifício narrativo, não intervirá na realidade histórica, ao menos em termos programáticos. Posta em cena, entretanto, é passível de estimular afetos identitários, convocar memórias e suscitar novos juízos sobre um evento que forjou subjetividades, mesmo que parcialmente à revelia daqueles que o vivenciaram.

A possibilidade de fundar correspondências entre o legado de um passado histórico e a ressignificação da experiência no presente enunciativo é um dos vínculos dessa comunidade composta por individualidades "permutáveis", no sentido de terem sido igualmente afetadas pelo anonimato - condição que, paradoxalmente, as habilita a enunciar a partir do lugar do "qualquer um", ou seja, do indivíduo capaz de experimentar, pela linguagem, uma autêntica experiência de si (AGAMBEN, 1993).

A personagem Nancy, rememorando a vivência de ter sido removida da casa onde morava, alude a um dos emblemas dessa violência: o " $x$ " marcado nos barracos que deveriam ser desocupados durante a Campanha de Erradicação de Invasões. Dildu, em sua atuação como candidato a deputado, adota na atualidade o mesmo " $\mathrm{x}$ " à guisa de marca distintiva de sua campanha, defendendo literalmente a ressignificação do símbolo: intervenção estética que, ao "reformar" certo modo de ver (e de fazer ver), faz com que os sujeitos possam experimentar ficções existenciais mais conformes a seus desejos latentes.

Tais estratégias autoficcionais, por estabelecerem relações inextrincáveis com experiências que remontam em chave polêmica a um tempo passado cujos efeitos se 
delineiam no presente, suscitam o exame de outro recurso discursivo fundamental em $A$ cidade é uma só?: o já referido trabalho com materiais de arquivo. Como princípio de enunciabilidade (FOUCAULT, 2008), modulando a formação e a transformação de determinados enunciados em épocas históricas distintas, o arquivo legitima certas narrativas em detrimento de outras e pressupõe um exercício de seleção que trabalha tanto pela inclusão quanto pela exclusão dos fragmentos que compõem um conjunto documental. Em contrapartida, o valor de autenticidade atribuído a esses materiais remete a um "isso aconteceu", estatuto de verdade histórica que, a cada época, fixa valores às práticas coletivas.

\section{A história retorcida pelas histórias: quando a experiência interroga o arquivo}

$\mathrm{O}$ som de um arquivo radiofônico alude à "cidade que JK construiu com tanto entusiasmo", que "vive como grande metrópole". A impostação própria à locução ajuda a ancorar esta voz no tempo e indicia seu valor de documento. Por meio de legendas, que identificam a voz como sendo a do arquiteto Oscar Niemeyer, completa-se o efeito de autoridade enunciativa. A imagem de cobertura, todavia, apresenta o título do documentário e o grafismo de um " $\mathrm{x}$ ", que, como referimos, o próprio filme trataria de contextualizar e de recontextualizar conforme a associação do marcador aos personagens Nancy e Dildu. Mais do que isso, em sentido estrito, o " $x$ " conota uma rasura ou uma anulação - e a interrogação componente do título do documentário antecipa a contradição entre um outrora mítico e um agora que não estendeu a todos as vantagens da modernidade e do progresso.

Um carro então vagueia no escuro, mas a estrada de terra inviabiliza a ideia de "grande metrópole". Entrecortada pelos chiados do rádio do carro, a voz volta a enunciarOra a literalidade das palavras "fé inquebrantável e consciência sem limites em seu grande destino" articula-se ao deslocamento do automóvel até percebermos se tratar da Ceilândia, "uma quebrada de responsa", pela letra de um rap entoado por jovens (entre eles Dildu e a namorada) ao redor de uma fogueira.

Se a sequência é tão exemplar, é porque sintetiza um procedimento estético de $A$ cidade é uma só? quanto à profusão de narrativas que deram corpo ao surgimento de Brasília. Não há como livrar as pequenas histórias cotidianas de uma história oficial, que determinou a essas vidas um lugar na ordem dos acontecimentos. 
Se a própria experiência pretérita pode, como empreendimento do filme, ser recontada, isso não se faz senão em friç̧ão permanente com uma herança: os relatos estabelecidos e as imagens que se dispersaram para dar compleição a uma macronarrativa urbanística e social de caráter épico. As faixas sonoras e visuais que se justapõem na sequência são tão indissociáveis quanto o passado o é do presente - e tão heterogêneas quanto os ritmos que hoje compassam a relação dos sujeitos do filme com a cidade.

É pela força dessa contradição constitutiva que os personagens se afirmam na diegese do documentário. 0 próprio contexto de produção, por ocasião do quinquagésimo aniversário da Capital Federal², propulsiona tal efeito de sentido, visto que as cinco décadas decorridas desde a "aventura épica" dão a ver histórias até então invisíveis, estabelecendo outros feixes de significação entre aquilo que se viveu e o registro da experiência. Com isso, os atores sociais podem, situadamente, assumir o protagonismo em relatos em que até então eram dispostos como representação da massa anônima.

Sob essa perspectiva, o encontro ou o confronto dos sujeitos com os materiais de arquivo, que instituíram o sentido "mais autorizado" daquilo que foi experienciado, dinamiza a possibilidade de ressignificação do vivido e do próprio papel de certos registros sonoros e imagéticos que, estabelecidos como testemunhos de um momento histórico, recobriram-se de um valor de verdade referencial.

A ironia, fenômeno expressivo que se constrói via uma disparidade de expectativas e um desencontro de pressupostos no fio condutor dos discursos, frequentemente é o efeito mais contundente do trabalho de interrogação do arquivo em A cidade é uma só?. A faixa sonora que denota a "aventura épica" de Brasília corresponde à faixa imagética de um plano-sequência em que Dildu dorme dentro de um ônibus e, posteriormente, aparece desempenhando a função de faxineiro; porém, esta investida de torção dos arquivos e versões oficiais é também o que faculta aos personagens e à própria escritura fílmica a virtualidade de forjarem, a seu modo, uma "aventura épica" particular, a redenção possível.

A presença recorrente dos documentos, nos termos da citação, evidencia a remetência a um chão histórico comum aos protagonistas e a configuração de algum senso de pertença coletiva, sem o quê qualquer possibilidade de dissenso não vigoraria. Há, assim, modulações de uma relação afetiva entre os personagens e versões corporificadas da história, polêmica

\footnotetext{
2 Uma indicação em letreiros no início do documentário informa que o filme foi parcialmente realizado com recursos de um Edital do Ministério da Cultura e da TV Brasil, com a temática “Brasília: 50 anos”.
} 
na medida em que muitas vezes reflete a ambivalência entre a adesão e o repúdio pelos sujeitos do filme quanto às narrativas (con)formadoras.

Se retomarmos o sentido foucaultiano de arquivo como princípio de enunciabilidade, será possível situarmos o conceito como um sistema que institui os enunciados tanto como acontecimentos (na medida em que rege suas condições de aparecimento) quanto como coisas (pois circunscreve o campo de utilização desses mesmos enunciados). 0 arquivo, então, não se fundamenta simplesmente pelo acúmulo de fragmentos em uma massa amorfa nem pela organização linear dos enunciados. Sendo uma espécie de lei que regula o que pode ser dito, e tende ao agrupamento das formas expressivas em figuras distintas, que mantêm entre si relações polêmicas, heterogêneas. É em conformidade com essas regras que nos expressamos e nos comunicamos, já que o arquivo delimita as condições de existência e coexistência dos discursos, assim como as gradações de adesão ou de repúdio que mantêm entre si e até mesmo suas condições de desaparecimento (FOUCAULT, 2008).

A ambivalência constitutiva do arquivo como sistema de enunciação se expressa no documentário quando Nancy, ao cantar na rádio, empresta a mesma emotividade tanto à interpretação do antigo jingle "A cidade é uma só" quanto à canção "Postal do Plano", de Rai Melodia, que denota, de forma crítica, o que foram os tempos inaugurais da Capital para a população pobre ${ }^{3}$ que oscilava entre a projeção de viver no Plano Piloto e a retórica das autoridades sobre uma vida "decente" nas cidades-satélite. Analogamente, a personagem se comove ao manipular, no arquivo de um jornal, fotografias da época das remoções. Não há revolta, mas reflexão crítica.

Paralelamente, Nancy revive os dias em que, ainda criança, participara da propaganda oficial que anunciava a Campanha de Erradicação de Invasões. Em uma reencenação do evento, ela interage com as "pequenas atrizes", dando instruções sobre a forma "correta" de se costurar os uniformes e de se arrumar os cabelos de acordo com a moda daquela época. Identifica-se com uma das meninas, notando a semelhança física entre as duas. Há um cuidado meticuloso na recomposição da cena, o que exorbita um propósito alusivo e tende mesmo à cópia dos detalhes formais. Tamanho apuro potencializa o desfecho da sequência: após uma claquete, as crianças riem para a câmera, mas a expectativa de ouvirmos suas vozes é frustrada. 0 "desvio" na cópia é fundamental em termos expressivos, como se o próprio curso da história pudesse ser alterado no documentário.

\footnotetext{
${ }^{3}$ Alguns versos da canção expressam: "Eu tinha plano de morar no Plano, de estudar no Plano. Era meu plano trabalhar no Plano [...]. Passados anos, tantas lutas, tantos planos, jogaram meus planos na periferia".
} 
Deslocando-se de um mundo sensorial a outro, ou ainda, instilando no "já-dito" o "contra-dito" (mais expressivo na sequência em questão na medida de um silêncio não aderente), A cidade é uma só? confronta certa ficção do poder com outras disposições e afetos para reconstruir narrativamente as histórias daqueles que conferiram valor singular a suas existências contra a indiferenciação pelo anonimato histórico.

\section{Conclusão}

A análise que busca circunscrever determinada manifestação artística em sua dimensão política tem de se haver com uma questão de fundamento: o parâmetro aqui não é o da possibilidade de uma intervenção direta da obra na realidade, no coração das relações de poder que conformam, por arranjos específicos, um dispositivo, ou seja, a "[...] disposição de uma série de práticas e mecanismos heterogêneos com o objetivo de fazer frente a uma urgência e obter um efeito". (AGAMBEN, 2005, p. 11), disciplinando os gestos e condutas dos indivíduos que compõem uma coletividade. Trata-se, então, de se perguntar se e como essa manifestação de arte estende a qualquer dos sujeitos a possibilidade de se afirmar a partir do anonimato, de reconfigurar sensorialmente seu próprio sentido existencial.

Paradoxalmente, as condições de reelaboração de experiências subjetivas não são alheias a uma relação dos seres com alguma forma de dispositivo. A dinâmica de uma arte essencialmente política, assim, tem no horizonte a produção de uma diversidade de dispositivos que restituam aos indivíduos uma virtualidade de subjetivação. Isso porque a multiplicidade de formas de subjetivação na contemporaneidade corresponde a uma proliferação bastante restrita de dispositivos, que operam essencialmente pelo esvaziamento das singularidades, e não por sua afirmação.

É como dispositivo que $A$ cidade é uma só? contempla uma urgência e um efeito. Compartilha com os personagens e com o espectador o princípio de devolver ao "uso comum" a atribuição de sentidos a práticas sociais e a eventos históricos narrativizados conforme uma disposição de poder que trabalhou para anular ou arrefecer expressões de subjetividade que colidissem com suas formas de exercício.

Se o recurso ficcional deliberadamente acolhido na tessitura documentária pode, em tese, apresentar-se como um princípio de hesitação no que diz respeito à crença do espectador e a seu engajamento no filme, isso se resolve, pensamos, pelo próprio caminho espectatorial no cinema documentário: "Trata-se, para ele [espectador], de duvidar de tudo o que parece estabelecido, de perceber a representação como uma realidade que se 
sobrepõe à realidade de referência para rivalizar com ela, transformá-la, miná-la ou colocála em dúvida." (COMOLLI, 2008, p. 274).

Fazer duvidar do dado da realidade - ao mesmo tempo em que se mostra necessária uma crença razoável nela, como construto que orienta nossos modos de existência - é o movimento ambivalente e fundamental do documentário. E o gesto da ficção, potente em $A$ cidade é uma só?, tende a engajar o espectador na ordem mesma da possibilidade: aquela que permite a redistribuição dos lugares sociais, fazendo ver e ouvir como expressões legítimas o que até então foram os ruídos e as imagens informes do anonimato.

\section{Referências}

AGAMBEN, Giorgio. A comunidade que vem. Lisboa: Presença, 1993.

AGAMBEN, Giorgio. 0 que é um dispositivo? Outra Travessia: Revista de Pós Graduação em Literatura, Florianópolis, n. 5, p. 9-16, 2005.

A CIDADE é uma só? Direção: Adirley Queirós. Produção: Adirley Queirós e André Carvalheira. Intérpretes: Nancy Araújo, Dilmar Durães (Dildu), Wellington Abreu e outros. Roteiro: Adirley Queirós. Música original: Guile Martins. Ceilândia: Ceicine, Cinco da Norte CEI, 400 Filmes, 2011. 1 DVD (79 min.), widescreen, cor. Produzido por Ceicine, Cinco da Norte CEI, 400 Filmes.

COMOLLI, Jean-Louis. Aqueles que (se) perdem. In: COMOLLI, Jean-Louis et al. Ver e poder: a inocência perdida: cinema, televisão, ficção, documentário. Belo Horizonte: UFMG, 2008. p. 269-282.

DELEUZE, Gilles. As potências do falso. In: . A imagem-tempo. São Paulo: Brasiliense, 2007. p. 155-188.

FOUCAULT, Michel. 0 enunciado e o arquivo. In: A arqueologia do saber. 7. ed. Rio de Janeiro: Forense-Universitária, 2008. p. 87-149.

FREIRE FILHO, João. Reinvenções da resistência juvenil: os estudos culturais e as micropolíticas do cotidiano. Rio de Janeiro: Mauad X, 2007.

MOSCOVICI, Serge. Representações sociais: investigações em psicologia social. 7. ed. Petrópolis: Vozes, 2010.

RANCIÈRE, Jacques. 0 desentendimento: política e filosofia. São Paulo: Editora 34, 1996.

RANCIÈRE, Jacques. A partilha do sensível: estética e política. São Paulo: Editora 34, 2005a. 
RANCIÈRE, Jacques. A política da arte: transcrição do seminário "São Paulo S.A., práticas estéticas, políticas e sociais em debate". São Paulo: SESC Belenzinho, 2005b. Disponível em: <http://www.sescsp.org.br/sesc/images/upload/conferencias/206.rtf>. Acesso em: 16 jul. 2014.

RANCIÈRE, Jacques. 0 espectador emancipado. São Paulo: WWF Martins Fontes, 2012.

SANTEIRO, Sérgio. A voz do dono: o conceito de dramaturgia natural. Filme e cultura, Rio de Janeiro, n. 30, p. 80-85, ago. 1978.

VANOYE, Francis; GOLIOT-LÉTÉ, Anne. Ensaio sobre a análise fílmica. 2. ed. Campinas: Papirus, 1994.

ZIZEK, Slavoj. Bem-vindo ao deserto do real! cinco ensaios sobre o 11 de setembro e datas relacionadas. São Paulo: Boitempo, 2003.

\title{
A cidade é uma só?: self-fictionalization, interrogation of archive and sense of dissensus
}

\begin{abstract}
Combining two filmic strategies - the self-fictionalization of characters and the resignification of the official archival materials - the Brazilian documentary A cidade é uma só? presents a radical critique to the discourse of power that covered the Invasion Eradication Campaign (Campanha de Erradicação de Invasões - CEI). The campaign was made to remove the poor that occupied the surroundings of Brasilia, that was under construction to become the latter Brazil's capital back in the 70s, therefore forming the so-called satellite towns.. This article analyses, by filmic materiality, how Adirley Queirós' documentary enables the resignification of a collective memory made by characters self-empowerment through the representation of themselves in conflict with the establishment of power. Hence, the filmic enunciation is therefore structured by the sense of dissensus, which is proper of political aesthetics (RANCIÈRE, 2005b).
\end{abstract}

\section{Keywords}

A cidade é uma só?. Documentary. Self-fictionalization. Archive. Dissensus. 